\title{
Type 2 Diabetes Mellitus in Adolescents: Should We Reconsider Screening?
}

\author{
Thomas Reinehr \\ Department of Pediatric Endocrinology, Diabetes, and Nutrition Medicine, Vestische Hospital for Children and \\ Adolescents, University of Witten/Herdecke, Datteln, Germany
}

Bacha et al. [1] analyzed the impact of many variables, including metabolic parameters, ethnicity, weight status, and social background, on the outcome of type 2 diabetes mellitus (T2DM) in a large dataset of adolescents. They reported that adolescents with a milder manifestation, only needing treatment with metformin, had a better outcome (defined by HbAlc levels $<7.5 \%$ four years after diagnosis) than adolescents with a more severe manifestation with initial insulin treatment. The strengths of this study are the relatively large number of patients with T2DM and the consideration of many variables that have been hypothesized to be associated with the outcome. Adolescents with good and worse outcomes did not differ with respect to age at manifestation, gender, degree of overweight, ethnicity, or comorbidities based on insulin resistance. Of interest, the outcome was not influenced by socioeconomic background as assessed by parental education and health insurances.

Most importantly, shorter diabetes duration and lower $\mathrm{HbAlc}$ at manifestation were associated with a better outcome [1]. One might argue from a statistical point of view that a milder manifestation is more likely to be mild also in the follow-up. However, we know that many adolescents with T2DM - also those treated with metformin

\section{KARGER}

๑ 2017 S. Karger AG, Basel

E-Mail karger@karger.com

www.karger.com/hrp alone - have a rapid deterioration of their glycemic control $[2,3]$. Therefore, the study by Bacha et al. [1] points towards the hypothesis that treating T2DM as early as possible may lead to a better outcome. Nearly half of the patients with a good outcome in this study demonstrated $\mathrm{HbA1c}$ levels $<7.5 \%$ at manifestation, suggesting that they were identified at onset of the disease. Moreover, in multiple regression analyses adjusting for many confounders, the identification of T2DM by screening was a predictor of a better outcome. In contrast to a more severe manifestation of T2DM, characterized by the classical symptoms of weight loss, polydipsia, and polyuria, early forms of T2DM are frequently overlooked in clinical practice if no screening is performed [4-6]. However, the current ISPAD guideline does not recommend screening for T2DM [7]. The authors argue that such a screening is not cost-effective. For example, a screening in Sweden has not identified any case of T2DM in obese children [8]. Of course, it is very unlikely to detect a child with T2DM by screening all overweight children regardless of their pubertal stage. Since the great majority of all T2DM cases in childhood are adolescents in puberty [4], screening for T2DM before puberty does not seem to be reasonable. Screening for T2DM in adolescents will be more effective if only high-risk pop- 
ulations are screened. High-risk populations are extremely obese adolescents or obese adolescents with a family history of T2DM and clinical features of insulin resistance/ metabolic syndrome, such as acanthosis nigricans, low HDL cholesterol levels, high triglycerides, arterial hypertension, and polycystic ovarian syndrome, as well as certain ethnicities (such as Asians, Hispanics, Native Americans, and African Americans) [9]. Screening such highrisk populations identified approximately 1 case of T2DM in 100 screened obese adolescents $[5,10,11]$. This detection rate is much higher than the detection rates of diseases in neonatal screening. Furthermore, populationbased studies have reported that every third case of T2DM in adolescents remains undetected $[5,6,12]$.

Since early treatment of T2DM is associated with a better treatment outcome in the analyses of Braha et al. [1], this is an important argument for screening for T2DM in high-risk adolescents. Therefore, we should reconsider screening for T2DM, which can be easily performed by HbAlc measurements in pubertal children in high-risk populations [13]. Furthermore, we should aim to treat T2DM effectively in the early course of the disease to achieve a robust endogenous insulin secretion and to preserve $\beta$-cell function. However, a crucial problem is the low treatment adherence in adolescents with T2DM [3, 14]. Further studies of this phenomenon are needed to overcome this barrier.

\section{Disclosure Statement}

The authors have no conflicts of interest to disclose.

\section{References}

1 Bacha F, Cheng P, Gal R, Kollman C, Tamborlane W, Klingensmith G, et al: Initial presentation of type 2 diabetes (T2D) in adolescents predicts durability of successful treatment with metformin monotherapy: insights from the Pediatric Diabetes Consortium (PDC) T2D Registry. Horm Res Pediatr 2017, DOI 10.1159/000481687.

2 Bacha F, Gungor N, Lee S, Arslanian SA: Progressive deterioration of beta-cell function in obese youth with type 2 diabetes. Pediatr Diabetes 2013;14:106-111.

3 Zeitler P, Hirst K, Pyle L, Linder B, Copeland $\mathrm{K}$, Arslanian S, et al: A clinical trial to maintain glycemic control in youth with type $2 \mathrm{di}$ abetes. N Engl J Med 2012;366:2247-2256.

4 Reinehr T: Type 2 diabetes mellitus in children and adolescents. World J Diabetes 2013; $4: 270-281$.

5 Demmer RT, Zuk AM, Rosenbaum M, Desvarieux M: Prevalence of diagnosed and undiagnosed type 2 diabetes mellitus among US adolescents: results from the continuous
NHANES, 1999-2010. Am J Epidemiol 2013; 178:1106-1113.

6 Lobstein T, Leach R: Diabetes may be undetected in many children in the UK. BMJ 2004; 328:1261-1262.

7 Craig ME, Jefferies C, Dabelea D, et al: ISPAD Clinical Practice Consensus Guidelines 2014. Definition, epidemiology, and classification of diabetes in children and adolescents. Pediatr Diabetes 2014;15(suppl 20):4-17.

8 Berhan YT, Mollsten A, Carlsson A, Hogberg L, Ivarsson A, Dahlquist G: Five-region study finds no evidence of undiagnosed type 2 diabetes in Swedish 11- to 13-year-olds. Acta Paediatr 2014;103:1078-1082.

9 Copeland KC, Zeitler P, Geffner M, Guandalini C, Higgins J, Hirst K, et al: Characteristics of adolescents and youth with recent-onset type 2 diabetes: the TODAY cohort at baseline. J Clin Endocrinol Metab 2011;96:159167.

10 Wiegand S, Maikowski U, Blankenstein O, Biebermann H, Tarnow P, Gruters A: Type 2 diabetes and impaired glucose tolerance in European children and adolescents with obesity - a problem that is no longer restricted to minority groups. Eur J Endocrinol 2004;151: 199-206.

11 Wabitsch $M$, Hauner $H$, Hertrampf $M$, Muche R, Hay B, Mayer H, et al: Type II diabetes mellitus and impaired glucose regulation in Caucasian children and adolescents with obesity living in Germany. Int J Obes Relat Metab Disord 2004;28:307-313.

12 Reinehr T, Kiess W, Kapellen T, Wiegand S, Holl RW: Children with diabetes mellitus type 2 in Europe: an underserved population. Arch Dis Child 2010;95:954.

13 American Diabetes Association: Classification and diagnosis of diabetes. Diabetes Care 2017;40(suppl 1):S11-S24.

14 Reinehr T, Schober E, Roth CL, Wiegand S, Holl R: Type 2 diabetes in children and adolescents in a 2-year follow-up: insufficient adherence to diabetes centers. Horm Res 2008; 69:107-113. 